\section{Shake-up essential}

THE policy-making procedures of the University of Cambridge, which have remained essentially unchanged since 1926, are slow, cumbersome and unsystematic, and must be altered if the university is not to lose out on research contracts and other valuable sources of income, according to an independent review group set up to examine the university's management.

Through its inability to act quickly, the university has "on more than one occasion" missed a promising opportunity to attract funds from external sources such as the research councils, says the report. It identifies the problem as a lack of delegation of authority. As a result, Regent House, the governing body, has become ineffective. Often, it is consulted about a proposal when it is already "too late to do anything but agree", says the report. When the Interdisciplinary Research Centre for superconductivity was set up, it was not possible to consult Regent House at all.

The review group recommends that the council should become the principal executive and policy-making body of the university. It also urged that the university and the colleges act in a more unified way.

The annual cost of the proposals would be $£ 350,000$. But the cost would be fully justified by the benefits that would flow from improved management of the university's resources, says the report. A university spokesman says a decision on the report is unlikely before the end of the year.

C. McG.

\section{Champagne physics}

THIS year's FF100,000 (\$15,000) Moet Hennessy-Louis Vuitton 'Science for Art' prize has been awarded to Pierre-Gilles de Gennes, for his work on the physics of surfaces and interfaces. Professor at the Collège de France and director of the Ecole de Physique et Chimie in Paris, de Gennes has contributed to a wide range of disciplines including superconductors, liquid crystals and polymer physics. The prize was established to acknowledge the debt to basic science owed by manufacturers of aesthetic and luxury products.

P.C.

\section{£31 million for IRCs}

THE UK Science and Engineering Research Council (SERC) is spending another $£ 31$ million on new interdisciplinary research centres (IRCs), one of the most recent innovations in the British pattern of research support. As a review gets under way into the effectiveness of IRCs in supporting research, SERC says that four more IRCs are to be set up: in polymer science at the University of Leeds; in process simulation, integration and control at Imperial College, London; and in optics and laser science at the University of Southampton. A fourth, in high performance materials, will be announced soon.

C. McG.

\title{
Australian code of practice
}

\section{Sydney}

Pressurf from animal welfare groups and the new ethical challenges set by genetic engineering have prompted a major revision of Australia's code of practice for animal experimentation. Changes agreed last week are claimed to make the new code the most stringent and comprehensive in the world.

Guidelines on animal experimentation were laid down originally by the National Health and Medical Research Council (NH and MRC) in 1969. Since then there have been three revisions, involving the Commonwealth Scientific and Industrial Research Organisation (CSIRO) and the Australian Agricultural Association (AAC).

The new code centres on the powers given to animal ethics committees. Each institution must appoint a committee consisting of a veterinarian, a scientist involved in animal experimentation, a member of the community not involved in research (although they may also belong to the institution or university), and "a person with a strong commitment to animal welfare." While each institution is responsible for appointing its own ethics committee, the committee members must be approved by the State Government's Department of Agriculture.

At present three states, New South Wales, Victoria and South Australia, have animal protection acts that back up the federal guidelines with state law. In these states, any researcher found by an ethics committee to be contravening the code of practice could face imprisonment on top of losing grants given by federal agencies. Australia's new code is remarkable for the power given to ethics committees. Each committee issues an approval number for all experiments and researchers cannot obtain an animal without citing this number. As an added control, State Government inspectors will make surprise checks on both researchers and ethics committees.

The code contains 23 general principles. Scientists must assume that animals experience pain in similar ways to humans and experiments should only be undertaken when there is no other way to obtain the required information. Scientists must also justify the number and species of the animal required and explain why techniques that do not use animals cannot be substituted. The code emphasizes that the use of death as a routine end-point or measure should not occur in toxiological experiments or when cancer is induced, unless absolutely necessary. Ethics committees can suspend experiments and treat or kill any animals if they see fit.

The code is the result of eighteeen months' work by staff of the $\mathrm{NH}$ and
MRC, CSIRO, AAC, the Royal Society for the Prevention of Cruelty to Animals, members of the general public, state government representatives and members of more than 500 interested parties, including animal welfare groups. Australia has seen little of the violent action of animal rights groups elsewhere (see, for example, page 407).

According to Warwick Anderson, chairperson of the NH and MRC Animal Experimentation Ethics Committee, this is because "there has been dialogue at both the State and Federal Government level. Many of the more radical animal rights groups are represented on ethics committees and are invited to attend research meetings." Despite being consulted, animal welfare groups are not entirely happy with the new code. Robyn Sullivan, President of the Humane Society and a member of the executive of the Australia and New Zealand Federation of Animal Societies says, "Our contributions have not been incorporated to the extent we would have liked".

"Post-operative pain relief will be given to experimental animals in line with veterinary practices but this is not consistent with the codes' provision for treating animals as though they experience pain like humans." A Senate inquiry into animal welfare is expected to present its findings to the Federal Government at the end of June. Convened in 1987 following pressure from animal welfare groups, the inquiry is expected to prompt the Federal Government to bring those states without appropriate animal protection laws into line with the rest of Australia.

Tania Ewing

\section{MUSEUMS}

\section{Improving image at no extra charge}

\section{London}

A THREE-month brush with a leading London-based firm of corporate image consultants has swept the halls of the British Museum (Natural History) with controversy. The museum will follow the recommendations suggested by image-makers Wolff Olins, including, at long last, an official change of name to the 'Natural History Museum' sometime this autumn. But recent newspaper reports that the museum intends to charge for expert advice to academic researchers or the public are "completely and utterly wrong", says a furious Neil Chalmers, the museum's director. The Wolff Olins report made no mention of charges, and researchers should be "reassured" that there are no plans to introduce charges for services that are now given freely.

Henry Gee 